\title{
A PERSPECTIVE ON THE USEFULNESS OF KNOWLEDGE ACQUIRED WITHIN A SIMULATED ENTERPRISE IN REVERSE ENGINEERING
}

\author{
Marius BABAN ${ }^{1}$, Calin Florin BABAN ${ }^{2}$, Alexandru Viorel PELE ${ }^{3}$ \\ ${ }^{1}$ University of Oradea, e-mail mbaban@uoradea.ro \\ ${ }^{2}$ University of Oradea, e-mail cbaban@uoradea.ro \\ ${ }^{3}$ University of Oradea, e-mail apele@uoradea.ro
}

\begin{abstract}
The project POSDRU/161/2.1/G/133930 "Support for a successful career in Reverse Engineering" was launched in 2014 aiming to develop the students' practical skills in the field of reverse engineering. The results of the activities of this project are intended to be employed as an input for the development of a new discipline called "Reverse Engineering". The most important knowledge to be acquired in a "Reverse Engineering" discipline has been identified considering the feedback of the beneficiaries of this project in the following areas: redesign of products; manufacturing and quality inspection of the products obtained through reverse engineering; and products data management in reverse engineering.
\end{abstract}

Keywords - reverse engineering, knowledge, usefulness, survey.

\section{INTRODUCTION}

$\mathrm{R}$ EVERSE engineering has been defined as "the process of extracting information about a product from the product itself" $[1$, p.1], which use a multidisciplinary knowledge approach to reconstruct, reproduce or preserve the original form of a product [2, p.1]. Due to the recent advance of the reverse engineering methods and technologies, industrial applications of reverse engineering are increasingly found in different fields [3, 4].

Since reverse engineering requires extensive knowledge from different disciplines [2, p.2], a human resource with a good training in reverse engineering is necessary, so that companies should benefit from their competencies. An example of the use of additive manufacturing and reverse engineering in engineering education based on interdisciplinary collaboration is presented in [5]. Despite its employment in industry, there are universities where didactical activities in reverse engineering are not offered in their undergraduate curriculum. In such cases, the learning method "simulated enterprise" [6] can be used to develop the knowledge and practical skills of the students in the field of reverse engineering.

\section{IDENTIFYING THE USEFULNESS OF KNOWLEDGE ACQUIRED WITHIN A SIMULATED ENTERPRISE IN REVERSE ENGINEERING}

\section{A. Problem Statement}

Since didactical activities in the field of reverse engineering are not provided at the University of Oradea, the project POSDRU/161/2.1/G/133930 "Support for a successful career in Reverse Engineering" was launched in 2014 [7]. The overall project objective was the development of the students' practical skills by performing activities within a Simulated Enterprise in Reverse Engineering (RE SE). This project involved two partners, University of Oradea as project's coordinator and S.C. RoMarketing S.R.L [7]. The results of these activities are intended to be employed as an input for the development of a new discipline called "Reverse Engineering", which will be taught in the future at the project's coordinator.

Therefore, the feedback of the beneficiaries of the POSDRU/161/2.1/G/133930 project has been considered important and the usefulness of the knowledge acquired through the training activities within the following departments of the RE SE was investigated among the participants of this project: a) redesign of products; b) manufacturing and quality inspection of the products obtained through reverse engineering and c) product data management in reverse engineering. A short description of the activities in each of these departments is described next. 
1) Redesign of the products. The initial product was scanned with the Shining $3 D^{\odot}$ Scaner, then was redesigned with the ShiningForm XOR software [8]. The ". stl" format, which is recognized by the $3 D$ printer was obtained through the Solid Edge software [8].

2) Manufacturing and quality inspection of the products obtained through reverse engineering. The products were manufactured using the $3 D$ printer Inspire ${ }^{\Theta}$ S200, while the quality inspection was carried out with the ShiningForm XOV software [8].

3) Product data management in reverse engineering. Activities in this department were performed with Teamcenter Engineering software. First, the Reverse Engineering virtual enterprise was created. Then, the product's structure was defined. Finally, the process flow of the tasks was described and workloads were assigned to employees in the departments of the virtual enterprise.

\section{B. Research Methodology}

A survey was conducted to identify the perception of the beneficiaries of the POSDRU/161/2.1/G/133930 project regarding the usefulness of the knowledge acquired through the training activities within the following departments of the RE SE:

1) redesign of products (11 items);

2) manufacturing and quality inspection of the products obtained through reverse engineering (11 items) and

$3)$ product data management in reverse engineering (12 items).

All the 81 beneficiaries of the training activities within the RE SE were asked to respond about the usefulness of the knowledge acquired in each of these departments. A five-point based Likert scale was used to establish the usefulness of the knowledge in each field (1=very few useful....5 =very useful). The survey was conducted during September-November 2015 and 51 beneficiaries responded to the questions of the survey.

The database of the responses was created within the Excel software, while the ToolPak of Excel was employed for statistical analysis of the data [9]. The arithmetic mean of each item was used to determine the usefulness of the knowledge acquired in each of the three departments of the RE SE.

The one-way ANOVA [10] was employed to find out the differences between the means in each department. If the results of the one-way ANOVA analysis show evidence that at least one of the mean statistically significantly differs from the rest of the means, the conservative Tukey's honestly significant difference (Tukey HSD) post-hoc test [10] was employed to evaluate which of any two pairs of means are significantly different.

\section{RESULTS}

A.The Establishment of the Usefulness of the Knowledge Acquired in the Departments D1.Redesign of Products

The values of the mean and the rank of the usefulness of the knowledge acquired in the department D1. Redesign of products are presented in Table I. Based on the data shown in Table I, the item D1_C2 has the highest mean $\left(\mathrm{m}_{\mathrm{D} 1 \_\mathrm{C} 2}=4.7\right)$, while the item D1_C3 has the lowest mean $\left(\mathrm{m}_{\mathrm{D} 1} \mathrm{C} 3=3.62\right)$. The $\mathrm{F}$ statistic of the ANOVA test was computed and resulted equal to $\mathrm{F}_{\mathrm{D} 1}=13.134(\mathrm{P}$-value $\mathrm{p}<0.001)$.

TABLE I.

The Values of the Mean and the Rank of KNowledge AcQuiRed in the DePartment D1. Redesign of Products

\begin{tabular}{|c|c|c|c|}
\hline Item No. & $\begin{array}{l}\text { Knowledge acquired through the activities in the } \\
\text { department D1. Redesign of products }\end{array}$ & Mean & Rank \\
\hline D1_C1 & $\begin{array}{l}\text { Knowledge regarding the employment of scanning methods of a the product using the 3D } \\
\text { OptimScan and Shining } 3 \mathrm{D}^{\odot} \text { Scaner software }\end{array}$ & 4.58 & 3 \\
\hline D1_C2 & $\begin{array}{l}\text { Knowledge regarding the acquirement of the points cloud of the product using the 3D } \\
\text { OptimScan and Shining } 3 \mathrm{D}^{\odot} \text { Scaner software }\end{array}$ & 4.7 & 1 \\
\hline D1_C3 & Knowledge regarding the export of the points cloud of the product in a RGE file format & 3.62 & 11 \\
\hline D1_C4 & $\begin{array}{l}\text { Knowledge regarding the import of the points cloud of the product (RGE file format) in the } \\
\text { Shiningform XOR software }\end{array}$ & 4.4 & 6 \\
\hline D1_C5 & $\begin{array}{l}\text { Knowledge regarding the transformation of the points cloud of the product in regions using } \\
\text { the Shiningform XOR software }\end{array}$ & 4.42 & 5 \\
\hline D1_C6 & $\begin{array}{l}\text { Knowledge regarding the employment of Shiningform XOR software to obtain the solid } \\
\text { model of the product }\end{array}$ & 4.5 & 4 \\
\hline D1_C7 & $\begin{array}{l}\text { Knowledge regarding the export of the solid model of the product from Shiningform XOR } \\
\text { software in a STEP file format }\end{array}$ & 3.7 & 10 \\
\hline D1_C8 & $\begin{array}{l}\text { Knowledge regarding the import of the solid model of the product (STEP file format) in the } \\
\text { Solid Edge software }\end{array}$ & 3.76 & 7 \\
\hline D1_C9 & $\begin{array}{l}\text { Knowledge regarding the employment of the Solid Edge software to modify the solid model } \\
\text { of the product }\end{array}$ & 4.68 & 2 \\
\hline D1_C10 & $\begin{array}{l}\text { Knowledge regarding the export of the solid model of the product from Solid Edge software } \\
\text { in a STL file format }\end{array}$ & 3.74 & 8 \\
\hline D1_C11 & $\begin{array}{l}\text { Knowledge regarding the export of the solid model of the product from Solid Edge software } \\
\text { in a IGS file format }\end{array}$ & 3.72 & 9 \\
\hline
\end{tabular}

Because the critical region is $\mathrm{F}_{\text {crit-D1 }}=1.847$ and $\mathrm{F}_{\mathrm{D} 1}>$ $F_{\text {crit-D1 }}$, a clear evidence was found that at least one of the mean of the D1_Ci knowledge $(i=\overline{1 \ldots 11})$ differs from the rest of the means (at 0.05 significance level). The employment of the Tukey HSD post-hoc indicates a significant difference between the mean of each item D1_Ci (i=1, 2,4,5,6,9) and the mean of each item D1_Ci $(\mathrm{i}=3,7,8,10,11)$. 
Therefore, each D1_Ci knowledge $(i=1,2,4,5,6,9)$ has been considered important to be acquired in a "Reverse Engineering" discipline.

B. The establishment of the usefulness of the
knowledge acquired in the departments D2.Manufacturing and quality inspection of the products obtained through reverse engineering

The values of the mean and the rank of the usefulness of the knowledge acquired in the department D2. Manufacturing and quality inspection of the products obtained through reverse engineering are shown in Table II.

In the case of the manufacturing of the products through reverse engineering, the higher mean was reported for the item D2_M_C4 $\left(\mathrm{m}_{\mathrm{D} 2 \_\mathrm{M}} \mathrm{C} 4=4.68\right)$, while the lower mean was reported for the item D2_M_C1

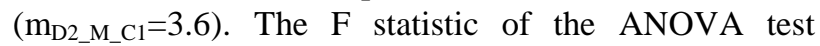
resulted equal to $\mathrm{F}_{\mathrm{D} 2 \mathrm{M}}=15.531$ ( $\mathrm{P}$-value $\left.\mathrm{p}<0.001\right)$, while the critical region is $\mathrm{F}_{\text {crit-D2 } \mathrm{M}}=2.407$. Therefore, $\mathrm{F}_{\mathrm{D} 2 \_\mathrm{M}}>\mathrm{F}_{\text {crit-D2_M }}$ so that there is clear evidence that at least one of the mean of the D2_M_Ci knowledge ( $\mathrm{i}=\overline{1 . .5}$ ) is significantly different from the rest of the means (at 0.05 significance level). The use of the Tukey HSD post-hoc indicates a significant difference between the mean of each item D2_M_Ci $(i=2,3,4)$ and the mean of each item D2_M_Ci (i=1,5).

In the case of the quality inspection of the products obtained through reverse engineering the higher mean was reported for the item D2_Q_C10 $\left(\mathrm{m}_{\mathrm{D} 2 \_\mathrm{Q}} \mathrm{C} 10=4.62\right)$, while the lower mean was reported for the item D2_Q_C6 (m $\left.\mathrm{m}_{\mathrm{D} 2 \mathrm{Q} \_\mathrm{C} 6}=3.54\right)$. The $\mathrm{F}$ statistic of the ANOVA test resulted equal to $\mathrm{F}_{\mathrm{D} 2 \mathrm{Q}}=15.131$ (P-value $\mathrm{p}<0.001)$, while the critical region is $\mathrm{F}_{\text {crit- } \mathrm{D} 2 \mathrm{Q}}=2.244$. Therefore, $\mathrm{F}_{\mathrm{D} 2 \_\mathrm{Q}}>\mathrm{F}_{\text {crit-D2_Q }}$ so that there is clear evidence that at least one of the mean of the D2_Q_Ci knowledge $(i=\overline{6 . .11})$ is significantly different from the rest of the means (at 0.05 significance level). The use of the Tukey HSD post-hoc indicates a significant difference between the mean of each item D2_Q_Ci $(i=7,8,10,11)$ and the mean of each item D2_Q_Ci $(i=6,9)$.

Consequently, each D2_M_Ci $(i=2,3,4)$ and D2_Q_Ci $(\mathrm{i}=7,8,10,11)$ knowledge has been considered important to be acquired in a "Reverse Engineering" discipline.

TABLE II.

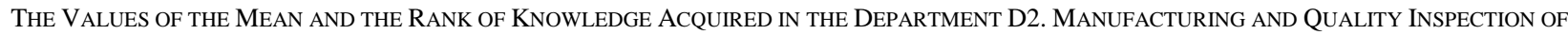
THE PRODUCTS OBTAINED THROUGH REVERSE ENGINEERING

\begin{tabular}{|c|c|c|c|}
\hline Item No. & $\begin{array}{l}\text { Knowledge acquired through the activities in the department D2. } \\
\text { Manufacturing and quality inspection of the products obtained } \\
\text { through reverse engineering }\end{array}$ & Mean & Rank \\
\hline \multicolumn{4}{|c|}{ D2_M. Manufacturing of the products through reverse engineering } \\
\hline D2_M_C1 & $\begin{array}{l}\text { Knowledge regarding the import of the solid model of the product from } \\
\text { Solid Edge software (STL file format) in the ModelWizard software of the } \\
\text { 3D printer Inspire }{ }^{\odot} \text { S200 }\end{array}$ & 3.6 & 5 \\
\hline D2_M_C2 & $\begin{array}{l}\text { Knowledge regarding the alignment of the product and change of its } \\
\text { position for material saving }\end{array}$ & 4.48 & 2 \\
\hline D2_M_C3 & Knowledge regarding the setting of the printing height & 4.4 & 3 \\
\hline D2_M_C4 & Knowledge regarding the establishment of the slicing parameters & 4.68 & 1 \\
\hline D2_M_C5 & $\begin{array}{l}\text { Knowledge regarding the establishment of printing properties of the 3D } \\
\text { printer Inspire }{ }^{\mathbb{S}} \mathrm{S} 200\end{array}$ & 3.76 & 4 \\
\hline \multicolumn{4}{|c|}{ D2_Q. Quality inspection of the products obtained through reverse engineering } \\
\hline D2_Q_C6 & $\begin{array}{l}\text { Knowledge regarding the import of the solid model of the product from } \\
\text { Solid Edge software (IGS file format) in the ShiningForm XOV software }\end{array}$ & 3.54 & 6 \\
\hline D2_Q_C7 & $\begin{array}{l}\text { Knowledge regarding the import of the products manufactured with the 3D } \\
\text { printer Inspire@ S } 200 \text { and scanned with the 3D OptimScan (RGE file } \\
\text { format) in the ShiningForm XOV software }\end{array}$ & 4.4 & 4 \\
\hline D2_Q_C8 & $\begin{array}{l}\text { Knowledge regarding the alignment of the manufactured product with its } \\
\text { 3D model }\end{array}$ & 4.52 & 2 \\
\hline D2_Q_C9 & Knowledge regarding the establishment of tolerances & 3.68 & 5 \\
\hline D2_Q_C10 & $\begin{array}{l}\text { Knowledge regarding the comparison of the manufactured product with its } \\
\text { 3D model }\end{array}$ & 4.62 & 1 \\
\hline 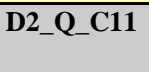 & $\begin{array}{l}\text { Knowledge regarding the generation of the quality inspection report of the } \\
\text { manufactured product with the 3D printer Inspire }{ }^{\mathscr{Q}} \text { S200 }\end{array}$ & 4.5 & 3 \\
\hline
\end{tabular}

C.The establishment of the usefulness of the knowledge acquired in the departments D3. Product data management in reverse engineering

The values of the mean and the rank of the usefulness of the knowledge acquired in the department D3. Products data management in reverse engineering are shown in Table III. As it is presented in Table III, the higher mean was reported for the item D3_C4 $\left(\mathrm{m}_{\mathrm{D} 3 \mathrm{C} 4}=\right.$
4.36), while the lower mean was reported for the item D3_C12 $\left(\mathrm{m}_{\mathrm{D} 3 \mathrm{C} 12}=3.12\right)$.

The F statistic of the ANOVA test resulted equal to $\mathrm{F}_{\mathrm{D} 3}=14.809$ ( $\mathrm{P}$-value $\mathrm{p}<0.001$ ). Since the critical region is $F_{\text {crit-D3 }}=1.804, F_{D 3}>F_{\text {crit-D3 }}$ and there is clear evidence that at least one of the mean of the D3_Ci knowledge ( $\mathrm{i}=\overline{1 \ldots 12}$ ) differs from the rest of the means (at 0.05 significance level). Tukey HSD post-hoc indicates a 
significant difference between the mean of each item D3_Ci $(i=3,4,5,9,11)$ and the mean of each item D3_Ci $(\mathrm{i}=1,2,6,8,12)$. Significant difference was also found between the mean of each item D3_Ci $(\mathrm{i}=7,10)$ and mean of each item D3_Ci $(i=1,2,8,12)$.
Within this context, each D3_Ci (i=3,4,5,7,9,10,11) knowledge has been considered important to be acquired in a "Reverse Engineering" discipline.

TABLE III.

The Values of the Mean and the RanK of Knowledge Acquired in the Department D3. Product data management in ReVerse ENGINEERING

\begin{tabular}{|c|c|c|c|}
\hline Item No. & $\begin{array}{c}\text { Knowledge acquired through the activities in the } \\
\text { department D3. Product data management in reverse engineering }\end{array}$ & Mean & Rank \\
\hline D3_C1 & $\begin{array}{l}\text { Knowledge regarding the Virtual Enterprise (VE) as a new type of } \\
\text { organization }\end{array}$ & 3.2 & 11 \\
\hline D3_C2 & $\begin{array}{l}\text { Knowledge regarding the interface and basic activities of the PLM software } \\
\text { platform Teamcenter" (TC) }\end{array}$ & 3.48 & 9 \\
\hline D3_C3 & $\begin{array}{l}\text { Knowledge regarding the creation of the structure of the VE (departments } \\
\text { and workstations) with TC - Groups, SubGroups, Rolls (Organization } \\
\text { application of TC) }\end{array}$ & 4.28 & 5 \\
\hline D3_C4 & $\begin{array}{l}\text { Knowledge regarding the creation of persons and users of the VE- Persons } \\
\text { and Users (Organization application of TC) }\end{array}$ & 4.36 & 1 \\
\hline D3_C5 & $\begin{array}{l}\text { Knowledge regarding the visualization of the parts and assemblies that were } \\
\text { modeled in 3D with the application "Teamcenter Visualization" }\end{array}$ & 4.34 & 2 \\
\hline D3_C6 & $\begin{array}{l}\text { Knowledge regarding the product's structure in a PLM system - the creation } \\
\text { of the directories structure-New Folder (MyTeamcenter application of TC) }\end{array}$ & 3.64 & 8 \\
\hline D3_C7 & $\begin{array}{l}\text { Knowledge regarding the creation and utilization of objects in the product's } \\
\text { structure - New Item (MyTeamcenter application of TC) }\end{array}$ & 4.24 & 6 \\
\hline D3_C8 & $\begin{array}{l}\text { Knowledge regarding the attachment of documents that described each Item } \\
\text { of the product's structure- Attached Files (MyTeamcenter application of TC) }\end{array}$ & 3.28 & 10 \\
\hline D3_C9 & $\begin{array}{l}\text { Knowledge regarding the processes (flows) in a PLM system - the creation } \\
\text { and visualization of the logical scheme with Template Wizard }\end{array}$ & 4.32 & 3 \\
\hline D3_C10 & $\begin{array}{l}\text { Knowledge regarding the creation of a new process-Workflow Process } \\
\text { (MyTeamcenter application of TC) }\end{array}$ & 4.2 & 7 \\
\hline D3_C11 & $\begin{array}{l}\text { Knowledge regarding the assignment of workload of the users of VE on the } \\
\text { product's structure - Assign All Tasks (MyTeamcenter application of TC) }\end{array}$ & 4.3 & 4 \\
\hline D3_C12 & $\begin{array}{l}\text { Final assessment of knowledge for use of a PLM software platform (TC)-VE, } \\
\text { product's structure, processes associated with the product }\end{array}$ & 3.12 & 12 \\
\hline
\end{tabular}

\section{CONCLUSION}

A survey was conducted to identify the perception of the beneficiaries of a training program within a Simulated Enterprise in Reverse Engineering regarding the usefulness of the knowledge acquired through the training activities within the following areas:

a) redesign of products;

b) manufacturing and quality inspection of the products obtained through reverse engineering;

c) product data management in reverse engineering.

Considering the feedback of the beneficiaries, the most important knowledge to be acquired in a "Reverse Engineering" discipline has been identified.

\section{ACKNOWLEDGMENT}

This research was in part undertaken within the project POSDRU/161/2.1/G/133930 "Support for a successful career in Reverse Engineering". This work was in part undertaken through the Partnerships in Priority Domains Programme-PN II, developed with the support of MENUEFISCDI, Project no. 337/2014.

\section{REFERENCES}

[1] S.P. Harston, C.A. Mattson (2010), "Metrics for evaluating the barrier and time to reverse engineer a product", Journal of Mechanical Design, 132/041009, pp. 1-9.
[2] W. Wego (2010.) Reverse Engineering: Technology of Reinvention, CRC Press, Taylor \& Francis.

[3] A. Afeez, Sanjay, A. Kumar (2013) "Application of CAD and reverse engineering methodology for development of complex assemblies", Journal of Engineering, Design and Technology, 11(3), pp. $375-390$.

[4] S.H. Mian, M.A. Mannan, A. Al-Ahmari (2015), "Accuracy of a reverse-engineered mould using contact and non-contact measurement techniques", International Journal of Computer Integrated Manufacturing, 28(5), pp. 419-436.

[5] G. Gatto, E. Bassoli, L. Denti, L. Iuliano, P. Minetola, (2015), "Multi-disciplinary approach in engineering education: learning with additive manufacturing and reverse engineering", Rapid Prototyping Journal, 21(5), pp. 598 - 603.

[6] M. Bianchi, L. Tampieri (2013), "Simulated Management in the Start-Up of New Public Organizations", Journal of US-China Public Administration, 10(5), pp. 475-487

[7] ***_ http://imtuoradea.ro/POSDRU_133930/, accessed on 1 November 2015.

[8] M. Baban, C.F. Baban, T. Buidos, I. Stanasel (2015) "A reverse engineering approach for the products development", Nonconventional Technologies Review, 19(1), pp. 12-17.

[9] C. Carlberg (2011). Statistical Analysis Microsoft Excel 2010 , Indianapolis, IN: Pearson Education, QUE.

[10] P. R. Hinton, (2004). Statistics explained (2nd ed.), London and New York: Routledge. 